\title{
Representação do Conhecimento gerado no Processo de Desenvolvimento de Software através de Storytelling
}

\author{
Leia F. Assis ${ }^{1,3}$, Carlos A M Pietrobon ${ }^{1,2}$ \\ ${ }^{1}$ PPGEE - Pontifícia Universidade Católica de Minas Gerais (PUCMG) \\ Av. Dom José Gaspar, 500 - Coração Eucarístico - 30.535-610 - Belo Horizonte - MG \\ - Brasil \\ ${ }^{2}$ DECOM - Universidade Federal de Ouro Preto (UFOP) \\ Campus Morro Cruzeiro - 34.400-000 - Ouro Preto - MG - Brasil \\ ${ }^{3}$ Centro Universitário Una (UNA) \\ leia.assis@gmail.com, capietro@pucminas.br, capietro@iceb.ufop.br
}

\begin{abstract}
The software development process is a set of activities that makes intensive use of knowledge and information. However, a lot of them are lost during the development effort or to stay in the people's mind. If someone need them, it will be very difficult to access them. Some times, it will be impossible. One reason for this is because is difficult to record and recover all the process knowledge in a fast and easy way. This article shows an approach to sharing the software development knowledge telling histories. It's an old human ability applied to a new context: software process.
\end{abstract}

Resumo. O desenvolvimento de software é um conjunto de atividades que faz uso intensivo de conhecimento e informação. Entretanto, muito destes são perdidos durante o esforço de desenvolvimento ou ficam na cabeça das pessoas. Se alguém necessitar deles, será muito difícil ou impossível obtê-los. Em parte isto acontece devido à dificuldade de se registrar e recuperar de forma rápida e intuitiva este conhecimento. Este artigo apresenta uma proposta para que o conhecimento relativo ao processo de desenvolvimento de software possa ser compartilhado através do mecanismo de contar histórias. Esse mecanismo é uma velha habilidade humana aplicada a um novo contexto: processo de software.

\section{Introdução}

No processo utilizado no dia-a-dia das organizações para prover diferentes tipos de produtos e serviços, aplica-se e constrói-se constantemente um conhecimento que precisa ser preservado e disseminado. Na busca constante de aliar produtividade à qualidade torna-se essencial que o conhecimento existente nas organizações, proveniente da experiência de mercado e das pessoas que fazem ou fizeram parte do seu corpo, seja gerado, mantido, aumentado e propagado.

Entretanto, nem todas as informações e a experiência dos membros da organização estão registradas de maneira explícita. Existem atividades e procedimentos que envolvem modelos mentais, crenças e perspectivas dos indivíduos, que não sabem expressar de forma articulada como executam essas ações. Esse tipo de conhecimento é 
definido como conhecimento tácito, e por ser de difícil articulação, sua documentação em papéis, arquivos, relatórios etc. é muito complicada (Nonaka e Takeuchi, 1997).

Como aponta Leal (2004), um dos maiores desafios da gestão do conhecimento é realizar o processo de externalização, isto é, transformar o conhecimento tácito, localizado na mente dos indivíduos, em conhecimento explícito, articulável e que pode ser facilmente expressado. Uma das formas de se ajudar neste processo consiste em fornecer ferramental adequado para se registrar e difundir o conhecimento. No caso deste trabalho o recurso de contar histórias (storytelling) utilizando recursos multimídia.

Não diferente dos demais processos existentes nos variados ramos organizacionais, é indispensável gerir o conhecimento no processo de desenvolvimento de software (PDS). Martins (2004) argumenta ainda, que o desenvolvimento de software é uma atividade que possui um fluxo de trabalho relativamente variável, onde é difícil planejar antes de saber mais precisamente sobre o que vai ser produzido. O que pode ser facilitado se o conhecimento gerado durante o processo for preservado e disseminado.

O objetivo deste trabalho foi prover a representação do conhecimento com recursos que permitam construir, contar histórias (storytelling) sobre os fatos acontecidos durante todo o processo de desenvolvimento. O mecanismo de storytelling foi escolhido por ser simples, de fácil utilização e ter um alto potencial de representação do conhecimento. Basta lembrarmos que o ser humano sempre passou conhecimento sobre suas mais diversas atividades, contando histórias sobre as mesmas. Adicionalmente, esta história será contada utilizando recursos multimídia, que enriquecerão a história contada, facilitando o seu entendimento. Para tanto, o artigo está organizado nas seguintes seções: (1) Introdução. (2) Processo de Desenvolvimento de Software. (3) Gestão do Conhecimento. (4) Storytelling. (5) História sobre Processo de Software. (6) Modelos. (7) ProcStory - Uma ferramenta que permite a construção de histórias. (8) Trabalhos relacionados. (9) Considerações Finais. (10) Referências.

\section{Processo de Desenvolvimento de Software}

Para Fuggetta (2000) um processo de software é definido como um conjunto coerente de políticas, estruturas organizacionais, tecnologias, procedimentos e artefatos que são necessários para conceber, desenvolver, entregar e manter um produto de software.

Em [Falbo, 1998] são explicitados os itens que compõem o processo de desenvolvimento de software. Para o contexto deste trabalho, estabelecemos como itens que compõem o processo, os recursos, as atividades e os artefatos. Estes podem ser entendidos como a realização de atividades (ações) com o objetivo de construir produtos (artefatos), a partir de recursos (pessoas, ferramentas, equipamentos, etc.) necessários à construção do software. Independentemente da forma (ferramentas, documentação, etc.) com que este processo é instanciado ou executado, ou do seu grau de qualidade (maturidade), temos uma realidade problemática: as pessoas envolvidas no desenvolvimento precisam compreender o processo e ter conhecimentos específicos para realizarem suas atividades.

Infelizmente, como aponta Souza e Nunes (2008) processos de software são complexos e envolvem um grande número de pessoas com tarefas especializadas, equipes multidisciplinares e cronogramas de longo prazo. Esta complexidade dificulta a percepção do processo como um todo por parte dos profissionais envolvidos, os quais 
necessitam possuir um mecanismo que permita a visualização dos diversos elementos e fases que constituem o processo.

Tanto a compreensão do processo quanto os conhecimentos necessários à execução das atividades, que são pré-requisitos para o andamento do trabalho, geralmente não são facilmente obtidos pelos envolvidos na atividade. Ferramentas de gestão do conhecimento podem apoiar o processo de desenvolvimento de software neste aspecto.

\section{Gestão do Conhecimento}

Para entender o tema gestão do conhecimento bem como sua devida importância é necessário tratar, no contexto deste trabalho, dos conceitos relacionados às diferenças entre dados, informação e conhecimento. Ao se buscar o significado destas palavras, percebemos que não há distinção clara entre as mesmas, principalmente decorrente do contexto e da área. Na Ciência da Computação a discussão sobre estes conceitos se relaciona principalmente com as formas de representação e armazenamento.

Setzer (1999) define bem as diferenças entre estes conceitos sob a perspectiva da Computação. Dado é como uma seqüência de símbolos quantificados ou quantificáveis. Portanto, um texto é um dado. Mesmo se incompreensível para o leitor, qualquer texto constitui um dado ou uma seqüência de dados. Informação é uma abstração informal que está na mente de alguém, representando algo significativo para essa pessoa. Uma distinção fundamental entre dado e informação é que o primeiro é puramente sintático e a segunda contém necessariamente. Conhecimento é caracterizado como uma abstração interior, pessoal, de algo que foi experimentado, vivenciado, por alguém. Um nenê de alguns meses tem muito conhecimento (por exemplo, reconhece a mãe, sabe que chorando ganha comida, etc.). Mas não se pode dizer que ele tem informações, pois não associa conceitos. Conhecimento está associado com pragmática, isto é, relaciona-se com alguma coisa existente no "mundo real" do qual se tem uma experiência direta.

Neste sentido, representa-se o conhecimento através de informações, ou seja, utilizando conceitos relacionados a símbolos e palavras. Por sua vez as informações são representadas através de dados. Desta maneira, tanto o conhecimento quanto à informação são representados usando dados que fazem algum sentido quando são vistos e interpretados.

Os recursos visuais podem ser utilizados para se buscar informações, mas também para se exibir resultados pesquisados, como por exemplo, o Kartoo [Kartoo, 2007]. Neste sentido, o mecanismo de contar histórias foi escolhido por se tratar de uma maneira natural de representação do conhecimento. Além disso, recursos visuais diversos bem como de navegação serão utilizados no auxílio de construção das histórias, ajudando a absorção e compreensão da mesma.

O objeto de estudo no qual se apóia a gestão do conhecimento aborda os conhecimentos tácito e explícito. Segundo Archibugi e Lundvall (2003) o conhecimento tácito não pode ser explicitado formalmente ou ser facilmente disseminado, refere-se aos conhecimentos implícitos, como as habilidades acumuladas por um indivíduo, organização ou o conjunto, que compartilham de atividades e linguagem comum. $\mathrm{O}$

conhecimento explícito é armazenado, memorizado, pode ser transacionado e 
transferido, além de poder ser reutilizado, reproduzido e comercializado indefinidamente. (Cowan e Foray, 1997)

De acordo com Nonaka e Takeuchi (1997) a criação de conhecimento nas organizações envolve as conversões dos diferentes tipos de conhecimento. Um dos maiores desafios da gestão do conhecimento é realizar o processo de externalização, transformando o conhecimento tácito que está na mente das pessoas em conhecimento explícito (Leal, 2004).

O objetivo deste trabalho foi desenvolver uma ferramenta que possibilitasse a conversão de conhecimento tácito em conhecimento explícito através de construção de histórias.

\section{Storytelling}

$\mathrm{O}$ ato de contar histórias faz parte da vida dos homens. E este recurso é uma forma simples e natural de transmitir conhecimento. Os seres humanos contam histórias para compartilhar experiências e casos. De forma similar, as organizações têm utilizado este recurso para possibilitar a transferência do conhecimento do seu corpo organizacional.

Toda organização, à medida que evolui, acumula uma série de experiências, casos e aprendizados associados à experiência adquirida pelas equipes e líderes. Porém, os artefatos gerados durante um projeto de desenvolvimento não trazem consigo os contextos e histórias pessoais que ajudaram na evolução da organização. Histórias são ricas em todos estes elementos e têm permeado a vida das organizações. [Terra, 2006]

Eventos são partes de uma história. Por exemplo, uma reunião, uma viagem, a assinatura de um contrato. Para Valle, Prinz e Borges (2002) uma narração de uma cadeia de eventos contada ou escrita em prosa e verso é uma história. Já no dicionário Michaelis a palavra história é definida como uma narração de acontecimentos, de ações, em geral cronologicamente dispostos [História, 2008]. Dentro da organização, contar histórias pode se tornar uma ferramenta eficaz de transmissão de conhecimento. Trata-se de uma antiga habilidade humana aplicada a um novo contexto: o contexto da gestão do conhecimento (Valle et al., 2003).

As histórias são capazes de simplificar e ajudar a transmitir um conhecimento complexo. A Harvard Business School tradicionalmente ensina assuntos complicados através do uso de narrativas, sob a forma de estudos de caso (cases) (Ruggles, 1999).

Neste sentido, percebe-se em storytelling um grande potencial para gestão do conhecimento gerado durante o processo de desenvolvimento de software.

\section{História sobre Processo de Software}

A solução apresentada para manipular conhecimento, se baseia na construção de histórias. Entretanto, esta história precisa ter uma estrutura narrativa, e precisa ter recursos para descrever fatos sobre os processos de software. Com relação à estrutura, Gancho (1991) define os cinco principais elementos que são componentes de uma narração: (1) Enredo: Conjunto de fatos que de uma história. (2) Personagem: Ser fictício ou não, que participa do enredo. (3) Tempo: Pode se referir tanto à época em que se passa a história quanto à duração da mesma. (4) Espaço: Local onde se passa. (5) Narrador: Autor da história, ou quem conta. 
Quanto à descrição dos fatos ocorridos durante o desenvolvimento, o stakehoder deverá utilizar termos definidos na ontologia do processo e ter recursos visuais que representem os elementos desta ontologia para narrar a história. Por exemplo, uma imagem que mostre um grupo em torno de uma mesa significaria uma reunião.

Vale lembrar que, segundo Chandrasekaran et al. (1999), uma ontologia pode ser entendida como uma representação do vocabulário de algum domínio ou problema. Mas não é o vocabulário que qualifica uma ontologia, e sim as conceituações que os termos do vocabulário pretendem capturar.

Lage (1993) afirma que a espinha dorsal da narrativa é a organização dos eventos em seqüências. Uma história pode ser dividida em eventos e o propósito da narrativa definirá a forma pela qual serão apresentados esses eventos. A reunião descrita anteriormente pode ser um evento de um enredo maior.

Considerando, que uma história é composta por eventos, e também têm os componentes descritos anteriormente: enredo, personagens, tempo, espaço e autor, os mecanismos para construção das mesmas deverão alocar esta estrutura. Na verdade, a estrutura é criada conforme o narrador conta a história. Ele é quem determina os eventos e a relação entre eles. Por exemplo, antes da reunião com o cliente, poderia ter sido narrado outro evento que seria uma reunião de fechamento da proposta comercial com personagens pertencentes à organização desenvolvedora.

Como o conhecimento está muito relacionado com a experiência, vivência, contar histórias provê um grande potencial para representação de conhecimento e conversão do conhecimento tácito para explícito. Porém, aproveitando-se do potencial da narrativa, ou seja, do mecanismo de contar história para retratar bem uma situação ocorrida ou uma experiência vivida, é importante ainda, elaborar uma história que não seja chata, que não seja difícil de ser visualizada. Desta maneira, a ferramenta proposta permite usar recursos de cores, textos, links, vídeos, sons, figuras e áudio para compor os diversos eventos na ordem mais apropriada para contar uma história.

Mas para gerenciar o conhecimento proveniente do processo de desenvolvimento de software é necessário vincular as histórias contadas a este processo permitindo a realização de pesquisas em torno de diferentes itens de conhecimento relacionados às atividades de desenvolvimento de acordo com a necessidade daqueles que estão as realizando. Assim, no momento em que história é criada as informações relativas ao processo na qual a mesma se refere devem ser fornecidas. Estas informações são usadas para a indexação da mesma e posterior localização. Assim uma história poderá ser localizada e visualizada, por projeto, por item de processo (atividade, recurso, artefato), por autor e por personagens e por palavras-chave diversas, que também são cadastradas para uma história registrada.

A ferramenta apresentada utiliza a junção de storytelling com o processo de desenvolvimento, provendo a gestão do conhecimento no processo de desenvolvimento de software.

\section{Modelos}

Conforme pode ser observado no diagrama de classes ilustrado na figura 1, um item de conhecimento pode ser do tipo Processo de Software ou pode não ter relação com o processo de desenvolvimento de software (Independente). Para o caso da história ser 
sobre o processo de software, poderá ser tanto sobre a definição de um processo quanto também sobre a execução de um processo (projetos usando processos definidos). Os demais itens do processo de software estão ligados às atividades que fazem parte do processo. Uma atividade possui sub-atividades, que usam artefatos (entrada no diagrama) e geram artefatos (saída no diagrama).

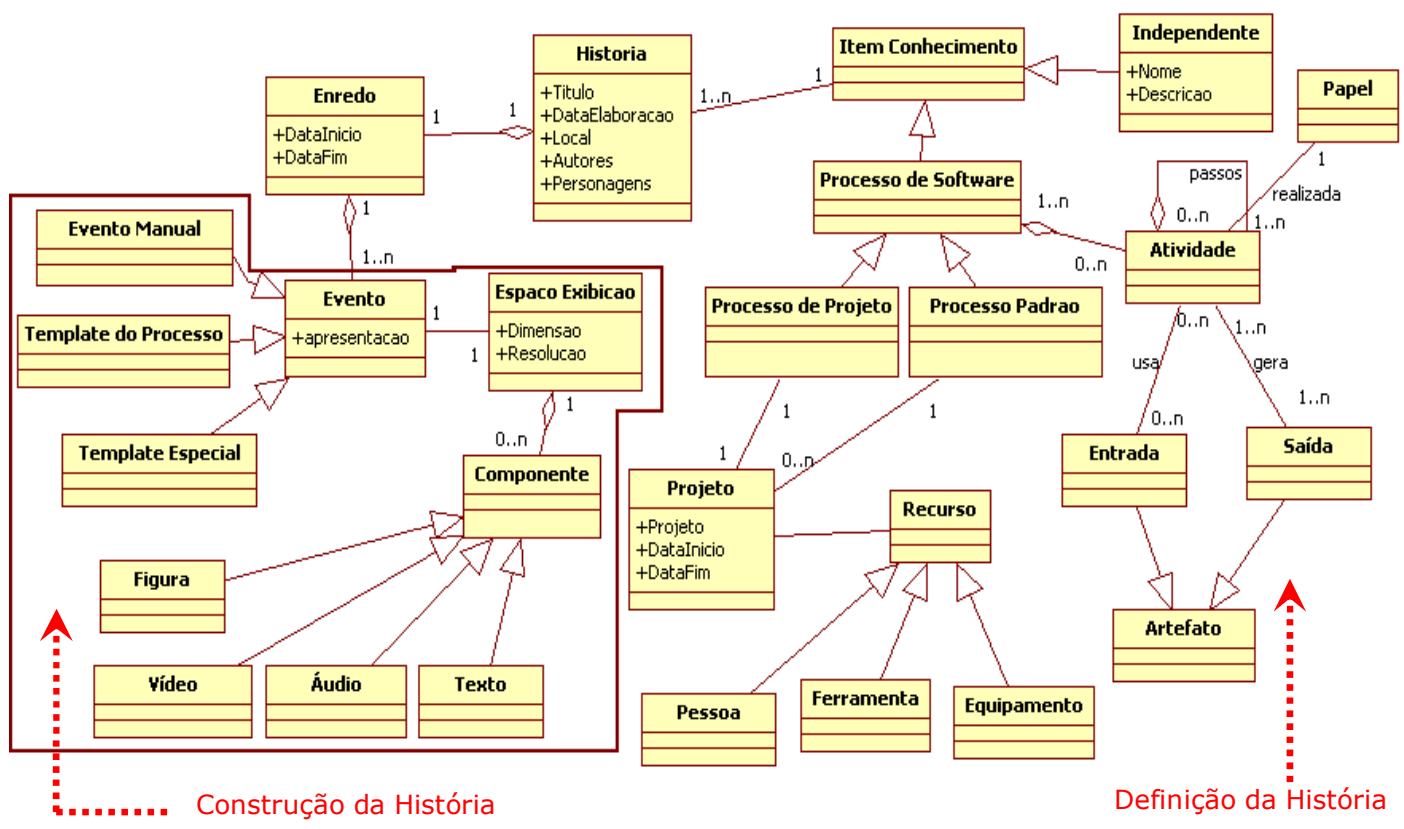

Figure 1. Diagrama de Classes da história relacionada ao desenvolvimento.

Qualquer atividade ou acontecimento relacionado ao processo de software envolvem um ou mais interessados ("stakeholders"). Estes envolvidos podem manifestar este conhecimento através de uma ou mais histórias relacionados a itens de conhecimento diversos sobre o desenvolvimento de software.

Por outro lado, cada item de conhecimento relacionado ao processo de desenvolvimento pode apresentar enredos variados, construídos por autores distintos. Cada enredo é um conjunto de fatos ou eventos que faz parte de uma história contada pelo autor e arrumada de uma forma conveniente para ser apresentada.

O diagrama de classes apresentado mostra a estrutura de uma história que poderá ser contada sobre qualquer item de conhecimento relacionado ao desenvolvimento de software. Esta terá uma autoria, possuirá personagens, data, local e ainda um enredo. $\mathrm{O}$ enredo é composto pelos eventos que a compõe. Cada evento é uma parte da história que é apresentada por tela (Espaço Exibição) e que poderá possuir diversos elementos. Cada elemento utilizado para construir o evento, utiliza recursos multimídia variados, como áudio, vídeo, imagens e texto.

Vale lembrar que apesar do registro das histórias serem realizados após a construção das mesmas, e após estas serem salvas, a publicação destas, bem como a disponibilização das mesmas para os demais envolvidos neste processo, dependerá da aprovação da mesma por um gerente. A figura 2 mostra este processo. 


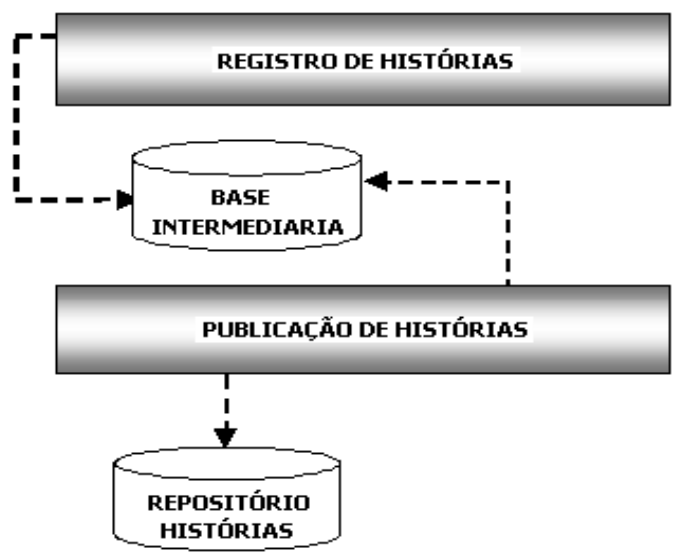

Figure 2. Publicação das Histórias.

\section{ProcStory - Uma ferramenta que permite a construção de histórias}

A ferramenta ProcStory foi construída para possibilitar a gestão do conhecimento no processo de desenvolvimento de software através da construção de histórias. Esta ferramenta está integrada ao Ambiente Discovery [Guedes, 2007] que é um ambiente web de visualização de conhecimento de processo de software.

A figura 3 ilustra a tela da ferramenta para quem conta (monta) uma história. Ao lado esquerdo da tela, são vistas as diferentes ações que o usuário pode realizar, referentes tanto a construção quanto a consulta das histórias.

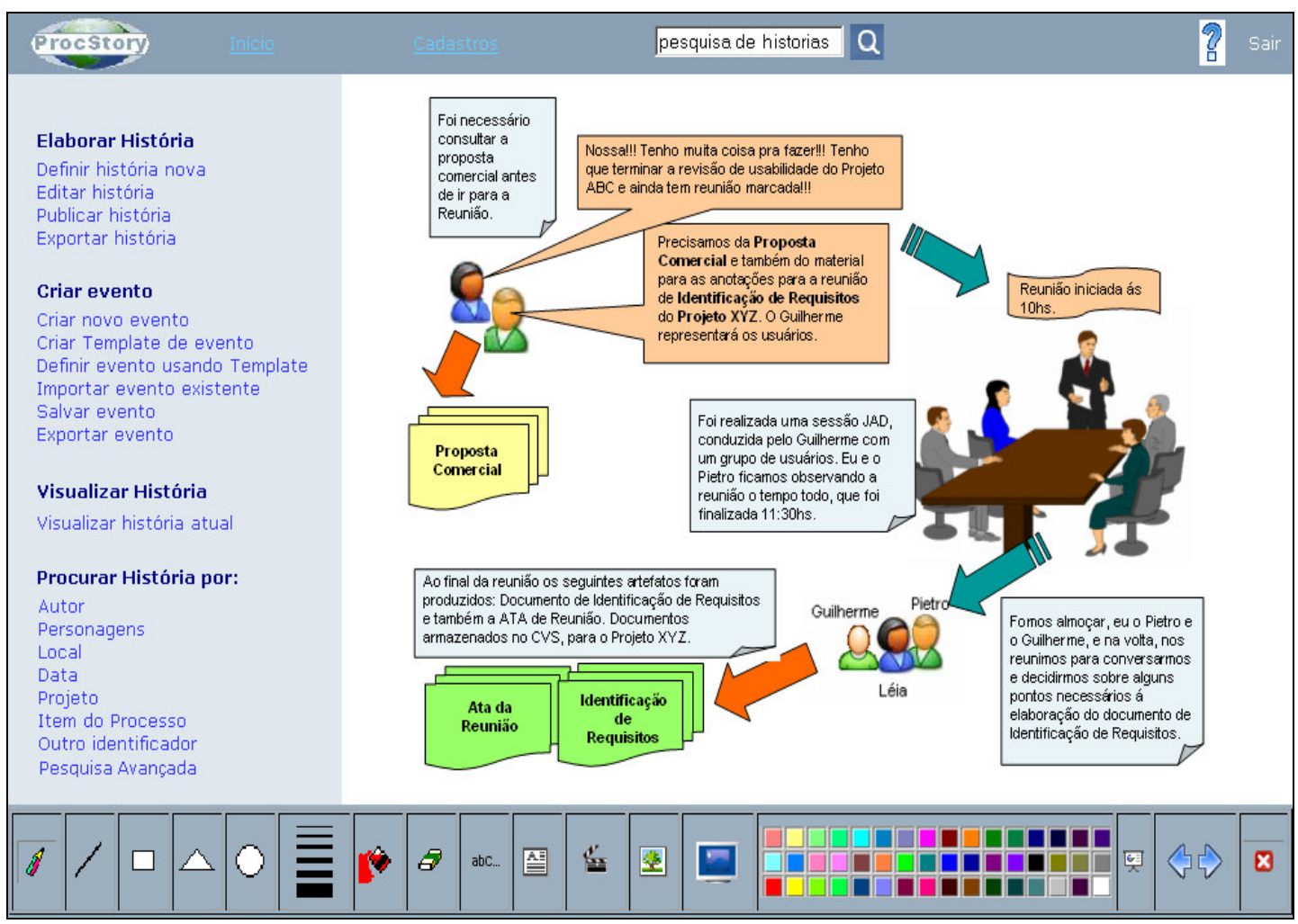

Figure 3. Tela principal da Ferramenta ProcStory. 
A barra de ferramentas, localizada na parte inferior da tela, contém os recursos elementares de visualização necessários para se construir a história, tais como filmes, fotos, sons, figuras, etc. Todos estes elementos são selecionados, posicionados na área de edição e instanciados apropriadamente, de forma a montar a história. No momento em que se inicia a criação da história, essa área é apresentada em branco.

Para entender melhor como os elementos construtores são adicionados a história, a seguir exemplificamos como ocorre a inclusão do elemento rótulo (um texto simples e não um texto grande) na história sendo construída. Uma vez que um rótulo foi selecionado na barra de ferramentas da figura 3, é apresentada a tela vista na figura 4. Para associar uma imagem, um som, um vídeo ou um hiperlink ao rótulo, basta clicar em um dos botões imagem..., som..., vídeo... ou hiperlink..., respectivamente. Ao se clicar em um destes botões, a tela é automaticamente expandida para que se possa selecionar a fonte multimídia que será associada ao rótulo inserido. Os demais elementos que podem ser utilizados para construção da história também são inseridos de forma similar.

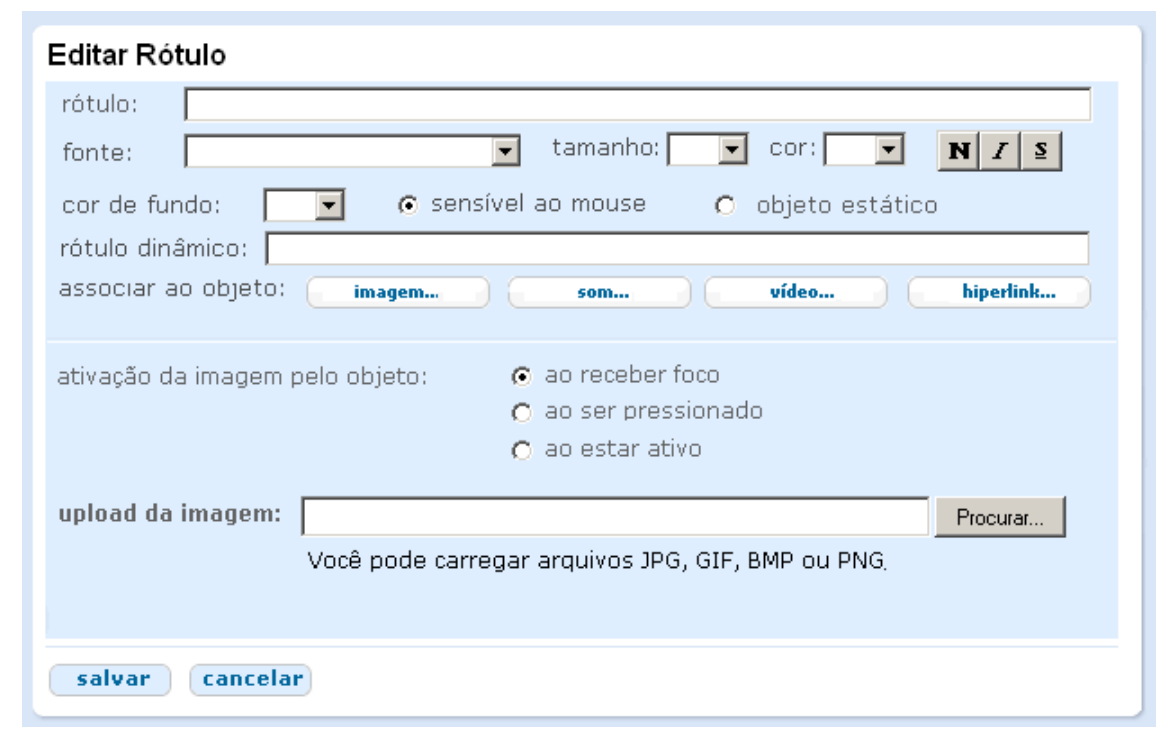

Figure 4. Tela Editar Rótulo.

Para que a história possa ser contada, ela precisa ser criada. Isto é feito utilizando a tela apresentada na figura 5. Nela são inseridas informações relativas à definição da história e também à associação da história com o processo e projeto de desenvolvimento de software.

A estruturação (organização entre os elementos) da história é construída conforme o Contador escreve a mesma. Alguns trechos podem ser mais detalhados, se necessário. Neste caso, outras telas poderão ser criadas para navegação. Neste caso fazse uso de links. Por exemplo, se a figura "ata de reunião" for clicado, tem-se acesso a ata da reunião em questão. Caso uma história tenha sido contada sobre esta ata, sua história pode ser acessada também.

Após as devidas informações para a definição de uma história serem inseridas, uma tela em branco é exibida e a história poderá ser construída utilizando os elementos e recursos contidos na barra de ferramentas. Outras telas poderão ser adicionadas na 
construção da história através da definição de novos eventos para aquela história. É criada uma tela para cada evento narrado que compõe a história. A navegação pela história pode acontecer de duas maneiras: indo para o próximo evento sequencialmente que foi encadeado quando a história foi criada ou seguindo um link que foi adicionado a um evento. A navegação na história por links permite que a história possa ser visualizada numa seqüência alternativa ou com diferentes níveis de profundidade. Caso não sejam utilizados os links para navegação na história, a mesma será exibida, de acordo com a ordem em que os eventos foram criados. Neste caso, a primeira a ser exibida é a tela principal, a que contém o primeiro evento. Depois é exibida a tela correspondente ao próximo evento criado e posteriormente os demais eventos criados na respectiva ordem.

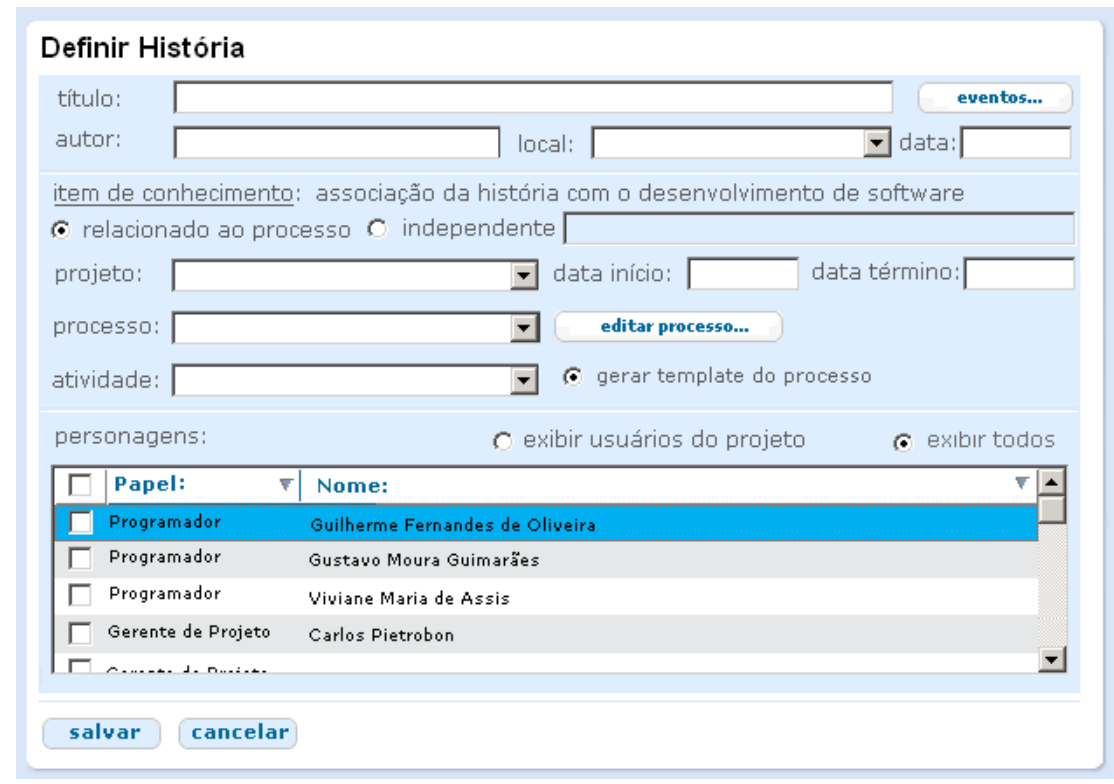

Figure 5. Tela Definir Nova História.

Desta maneira a história é construída, através de telas. E recursos variados, disponibilizados na barra de ferramenta da figura 3 poderão ser utilizados em cada tela, para construção da história e navegação nas mesmas.

Quando todas as histórias estiverem prontas, podem ser acessadas pelo Gerente de Conhecimento que realiza uma ou mais das atividades seguintes: (a) Monta a história final oficial. (b) Cria histórias apropriadas e adaptadas a cada categoria de usuário (por exemplo, histórias que são importantes para o gerente e as que são relevantes para o programador). (c) Publica uma história recebida (d) Constrói histórias apropriadas a necessidades.

\section{Trabalhos relacionados}

Pereira (2003) desenvolveu um trabalho com o objetivo de iniciar a discussão sobre um novo modelo de Engenharia de Software que fosse orientado á produção de conhecimento, distinto dos modelos atuais baseado nos diferentes tipos de conversões do conhecimento inseridos no processo de desenvolvimento de software. Assim, para prover a gestão do conhecimento neste processo é necessário prover mecanismos que 
permitam as conversões dos diferentes tipos de conhecimento. Como por exemplo, do conhecimento tácito para o explícito e do explícito para o tácito.

A Estação TABA é um ambiente de desenvolvimento de software que apóia a execução das atividades de desenvolvimento, utilizando ferramentas e repositórios que contém informações sobre a execução do processo de software. A partir de um processo padrão, ocorre o instanciamento para o processo específico de uma organização. Neste contexto, Montoni (2003), desenvolveu uma ferramenta de aquisição de conhecimento no processo de desenvolvimento de software denominada Acknowledge. Seu principal objetivo é apoiar a execução do processo de aquisição de conhecimento em atividades de engenharia de software, sendo possível registrar diferentes tipos de conhecimento que podem ser independentes ou não da execução de um processo.

Falbo (1998) desenvolveu um trabalho (ODE-Ontology based software development environment) com a meta de integrar conhecimento no processo de desenvolvimento de software, utilizando uma abordagem ontológica, onde se tem conceitos e relações, definições, propriedades e restrições em forma de axiomas sobre processos de software.

Tanto o TABA quanto o ODE trazem a preocupação em prover um ambiente de desenvolvimento de software, que facilite e auxilie as atividades de desenvolvimento considerando a gestão do conhecimento. Porém não usam a técnica de storytelling, e nem diferentes maneiras de representação do conhecimento.

Leal (2004) desenvolveu um trabalho usando storytelling que é a narrativa ou ato de contar histórias como mecanismo de disseminação do conhecimento, porém utilizando apenas recursos textuais.

Outro trabalho usando o mecanismo de contar histórias foi o Storytelling Alice, desenvolvido por Caitlin Kelleher como parte de seu trabalho de doutorado em Ciência da Computação. Alice é uma ferramenta que cria animações para contar histórias que pode ser utilizada para o ensino de introdução à computação. Usa gráficos 3D e uma interface mais envolvente, menos frustrante para a primeira experiência de programação. Utiliza um mecanismo de criar animações para contar histórias. Permite a criação de filmes adicionando objetos às cenas, que fazem parte do filme, e cada objeto é manipulado, conforme uma programação orientada a objetos. A cada objeto inserido na cena, é possível manipular as propriedades, métodos, funções, e, além disso, novas variáveis e parâmetros também podem ser criados. (Alice, 2008).

Por fim tem-se o Impulse [Burkhard 2005], um framework genérico para visualização de conhecimento em processos de negócio, baseado em conhecimento, formas de visualização, receptor do conhecimento e objetivo da visualização. $O$ ProcStory implementa os três primeiros conceitos uma vez que está voltado para a descrição visual de conhecimentos apropriados as diversas categorias de usuário em processos de software.

Já o presente trabalho, apresentado neste artigo, permite a construção de histórias vinculadas ao processo de desenvolvimento de software, fazendo uso de recursos multimídia para ilustrar a mesma, que desta forma será preservada, mantida, disseminada, recuperada e utilizada. 


\section{Considerações Finais}

A principal contribuição desta pesquisa foi desenvolver uma abordagem que permita registrar através de representações o conhecimento relacionado ao processo de desenvolvimento de software por meio da técnica de storytelling, conhecida há milênios, mas não aplicada à área de desenvolvimento de software e nem na qualidade de software. A construção de histórias é baseada na estrutura do texto narrativo e permite a utilização de recursos textuais, sonoros e visuais, que são associados ao processo de desenvolvimento de software, aos processos de qualidade ou a partes deles.

Além disso, o desenvolvimento do presente trabalho incentiva novas pesquisas sobre storytelling apoiando a representação do conhecimento gerado em qualquer tipo de organização e processo, como também nas organizações de desenvolvimento de software, e contribuindo para o processo de aprendizado, tanto na área acadêmica quanto em qualquer outra área.

Este trabalho apresenta uma ferramenta para contar histórias sobre processos de software. Seu objetivo é facilitar a troca de conhecimento entre os diversos interessados no desenvolvimento de software em um projeto e, num escopo mais abrangente, na organização como um todo. Esta história faz uso de recursos multimídia que permitem as pessoas escolherem as formas mais apropriadas de expressar os fatos que vivenciou e desta forma facilitar a transferência do conhecimento explícito, bem como o tácito.

\section{Referências}

Alice. 2008. www.alice.org. Carnegie Mellon University. [Online] Alice is made freely available as a public service, 2008. [Citado em: 10 de Agosto de 2008.] An Educational Software that teaches students computer programming in a $3 D$ environment.

Archibugi, D. e Lundvall, B. 2003. The Globalizing Learning Economy. s.1. : Oxford University Press, 2003.

Burkhard, R. A. (2005), "Impulse: Using Knowledge Visualization in Business Process Oriented Knowledge Infrastructures", Journal of Universal Knowledge Management, Vol. 0, No. 2, pp. 170-188.

Chandrasekaran, B., Josephson, J. R. e R., Benjamins V. 1999. What Are Ontologies, and Why Do We Need Them? IEEE Intelligent Systems. 1999.

Cowan R., Foray D. (1997), "Tacit knowledge and information: that the dynamics of codification are endogeneous", Working Paper, IRIS-IMRI, University of Paris Dauphine, 25p.

Falbo, R. A. (1998), "Integração de Conhecimento em um Ambiente de Desenvolvimento de Software", Tese de Doutorado. Programa de Engenharia de Sistemas e Computação da COPPE/UFRJ.

Fuggetta, A. "Software Process: A Roadmap", in Proc. of The Future of Software Engineering, ICSE'2000, Limerick, Ireland.

Gancho, C.V. (1991), “Como analisar narrativas”, São Paulo: Ática. 
Guedes, F. C. (2007), "Glifo para Verificação da Utilização de Processos de Requisitos por meio da Rastreabilidade como apoio à melhoria de Qualidade de Software”, submetido ao SBQS 2007.

História (2008), "Dicionário Eletrônico Michaelis", http://michaelis.uol.com.br/moderno/portugues. Último acesso em março de 2008.

Judelman, G. B. (2204), "Knowledge Visualization: Problems and Principles for Mapping the Knowledge Space", MSC Thesis Dissertation, Univerity of Lübeck, Germany, June.

Kartoo S. A. (2007), "Metamotor de pesquisa de Informação Web", http: / / www . kartoo. com, Último acesso em março de 2008.

Leal, R. P. (2004) "Técnica de Groupstorytelling aplicada à gestão do conhecimento", Dissertação de Mestrado. Rio de Janeiro. UFRJ.

Martins, J. C. C. (2005) "Gerenciando projetos de desenvolvimento de software com PMI, RUP e UML”, Rio de Janeiro, Brasport.

Montoni, M.A. (2003), “Aquisição de Conhecimento: Uma Aplicação no Processo de Desenvolvimento de Software", Dissertação de Mestrado, UFRJ.

Nonaka, I. e Takeuchi, H. (1997) "Criação de Conhecimento na Empresa", Rio de Janeiro. Campus.

Pereira, M. A. M. (2003), "Produção e Disseminação de Conhecimento na Engenharia de Software", Dissertação de Mestrado, Pontifícia Universidade Católica de Campinas, Programa de Pós-Graduação em Ciência da Informação.

Ruggles, R. (1999), "The role of stories in knowledge management". In: Journal of Storytelling and Business Excellence. Storytelling Foundation International.

Setzer, V. W. (1999) "Dado, Informação e Competência", Revista Eletrônica sobre Ciência da Informação Datagrama Zero,USP, Novembro.

Souza, A. L. R. e Nunes, D. J. (2008) "Uma ferramenta para Apoio a Visualização e Representação de Modelos de Processo de Software", http://www.inf.ufrgs.br/prosoft/rsrc/Prosoft/PublicatedWork20050908205225/Lincol nArtigoSemAcad.PDF, UFRGS, Março.

Terra, J. C. C. (2006), "Storytelling como ferramenta de gestão", http://www.terraforum.com.br/sites/terraforum/Biblioteca/Storytelling\%20como\%20 ferramenta\%20de\%20gest\%C3\%A3o.pdf, Terra Fórum Consultores, São Paulo.

Valle, C. et al. (2003), "Group storytelling to support tacit knowledge externalization". In: Proceedings of the 10th International Conference on Human - Computer Interaction. Crete, Grécia. Mahwah, New Jersey, USA: Lawrence Erlbaum Associates, Publishers, 2003, v. 4, p. 1218-1222.

Valle, C., Prinz, W. e Borges, M.R.S.(2002), "Generation of group storytelling in postdecision implementation process." In: Proceedings of the 7 International Conference on CSCWD. Rio de Janeiro, 2002. p. 361-367. 